\title{
Research on the Current Situation of the Protection of Agricultural Cultural Heritage in China
}

\author{
Wang Benxue, Jing Kun \\ College of Economics and Trade Management, Quzhou University, ZheJian, Quzhou, 324000
}

Keywords: agricultural cultural heritage; protection; sustainable development

\begin{abstract}
Agricultural cultural heritage is the foundation of Chinese civilization based on the inheritance. The exploration, protection and inheritance of agricultural cultural heritage will play an important role in promoting sustainable development of agriculture, increasing farmers' income in heritage sites, protecting agricultural ecological environment and spreading Chinese civilization. Compared with developed countries, China's protection of cultural heritage in agriculture started late, the government departments at all levels should actively implement the central document spirit, strengthen the importance to work, play a leading role in the establishment of social participatory mechanisms, strengthen the excavation and protection of important agricultural heritage
\end{abstract}

\section{The basic situation of agricultural cultural heritage}

Cultural heritage is a form of visible or intangible manifestation of the human way of life handed down from generation to generation. The forms of cultural heritage are human custom, human architecture, and human architecture.

Articles, art, etc. Agricultural cultural heritage is part of the cultural heritage and has all the characteristics of cultural heritage. Agricultural cultural heritage refers to the visible or invisible agricultural natural and cultural landscape formed in agriculture in the rural area, and its landscape has diversity and regionality.

Combined with the research of experts and scholars at home and abroad, the author thinks that agricultural cultural heritage should also include material agricultural cultural heritage and non-material agricultural cultural heritage, of which material agricultural cultural heritage is the means of production, and the intangible cultural heritage of agriculture is production technology[2].

In order to protect the agricultural cultural heritage, a set of evaluation and selection criteria should be set up first. Under the premise of not violating the guiding ideology of the United Nations Food and Agriculture Organization (FAO), according to the natural, social and economic conditions of our country, refer to FAO

The standard form of China's important agricultural heritage selection criteria: (1) the historical heritage still has strong production function, to provide protection for the local agricultural production, income and social welfare; (2) the traditional knowledge and technology of agricultural production or utilization, conservation of water and soil resources has many ecological functions implication. And landscape value; (3) reflects the harmonious development of man and nature philosophy, contains the wisdom of working people, the higher the value of cultural heritage; (4) facing the negative impact of human factors of natural disasters, climate change, biological invasions and natural factors such as urbanization, new agricultural technology, foreign culture, there is a risk of death.

\section{The status quo of the protection of agricultural cultural heritage in China}

China has a long history of agricultural development. In the long course of agricultural cultivation, various agricultural cultures have been formed in various parts of China. This has also resulted in the uneven distribution of Agricultural Cultural Heritage in China, and the number of provinces in different provinces. The number of Agricultural Cultural Heritages in Yunnan is top of the country, which is 63. Secondly, there are 50 items in Beijing, and 46 in Zhejiang and Shandong. 
The above four provinces (cities) have a long history of agricultural production and high agricultural production technology, so they have more agricultural cultural heritage than other provinces (cities). Jilin province is the province with the least number of Agricultural Cultural Heritages in China, with only 1 items. The number of Agricultural Cultural Heritages in Tianjin, Hainan, Tibet and Qinghai is also relatively small, only 3. Yunnan's unique physiognomy, diverse ecological resources, excellent natural environment and the production habits of the 26 nations in the world make its rich farming culture. Among 63 Agricultural Cultural Heritages in Yunnan Province, it includes both Mengzi sweet pomegranate and Yunnan Tengchong ginkgo cultivation system[3].

Tengchong Buffalo, Yunlong black goat and Yunlong piglet breeding system, including the whole agricultural ecosystem, such as Yunnan Tengchong ancient tea garden and tea culture system, Yunnan Binchuan walnut crop compound system, Yunnan Yunlong ditch irrigation agricultural system, etc.

Beijing has a long history of agricultural development, and the level of agricultural modernization is high. All districts and counties have special agricultural products, such as Yanqing grapes, Changping strawberries, Pinggu big peach and Mentougou cherry. Although the current stage of agriculture in all industries in Beijing is low, but the number of Agricultural Cultural Heritage in Beijing ranks the top in the country. The relevant departments of Beijing and the agricultural workers should pay attention to the protection and development of the Agricultural Cultural Heritage of Beijing[4].

In order to protect and carry forward the Chinese culture, promote the sustainable development of agriculture, enrich the development resources of leisure agriculture and increase the employment and income of farmers, the Ministry of agriculture has excavated and identified a number of important agricultural cultural heritage in China since 2012. Up to now, the 4 batch of Chinese important agricultural cultural heritage lists have been published, with a total of 91 items.

The first batch of important agricultural heritage projects include not only has selected globally important agricultural heritage project (GIAHS) of the large area of mountain rice agriculture production system, Yunnan Honghe Hani rice terraces system, traditional rice fish agricultural production mode -- Zhejiang Qingtian rice fish system, as well as the world dry farming source Inner Mongolia Aohan dry farming system efficient agricultural production system, steep mountains - Zhejiang Shaoxing Kuaiji mountain ancient Torreya, bamboo forest, swamp land use pattern in Jiangsu depression of Xinghua Duotian traditional agricultural systems etc.. The first important agricultural cultural heritage is a system which is integrated by various agricultural departments or various crops in various proportions and different ways[5].

The second batch of important agricultural cultural heritage projects are more carefully divided on the basis of the first agricultural system. Such as Hunan, Xinhuang, Yunnan Dong reservoir red rice cropping system in rice wheat cropping system of Yunnan Jianchuan, Guangnan Babao rice ecosystem; crop planting system, such as Tianjin, Hebei Binhai Cui Zhuanggu winter jujube chestnut cultivation system, Kuancheng traditional plate culture system, letinous edodes Zhejiang Qingyuan Sichuan Jiangyou magnolia flower and traditional cultivation system of Gansu, Minxian, angelica planting system Zhejiang Huzhou, Shandong Xiajin mulberry base pond system in the Yellow River old trees.

The third batch of important agricultural heritage, Beijing Pinggu four Building Ma walnut production system, Hubei Enshi Gyokuro tea culture system, Guizhou Huaxi ancient tea and tea culture system, Yunnan Shuangjiang Mengku ancient tea and tea culture system; Liaoning Huanren Beijing rent rice cultivation system, Guangxi Longan Zhuang "the culture" the rice culture system, Heilongjiang Ning composition system sound rice rice system; Jilin Yanbian apple pear cultivation system, Jiangsu Taixing, Zhejiang Xianju bayberry cultivation system of ginkgo cultivation system, Ningxia Zhongning wolfberry cultivation system of traditional cropping system; Heilongjiang Fuyuan Hezhe fish culture system, Zhejiang and Anhui, Shouxian County Shaobei terrace agriculture system (Anfeng reservoir) and irrigation system, Anhui Xiuning spring water fish culture system of agricultural complex system[6]. 
The fourth batch of important agricultural heritage including Hebei Qianxi Hebei booming chestnut composite cultivation system, traditional cultivation system, Shanxi Jishan Hawthorn jujube production system, we can make Inner Mongolia agriculture and animal husbandry production system, Jilin Heshan Liu grape cultivation system of Jilin nine Taiwan five Tun Gongmi cultivation system, Jiangsu Gaoyou Lake wetland agriculture system, Jiangsu Wuxi Yangshan peaches cultivation system Zhejiang Deqing, freshwater pearl culture and traditional utilization system, Anhui Tongling white ginger planting system in Anhui, Mount Huangshan Taiping Houkui Tea culture system, Fujian Fuding white tea culture system, Jiangxi, Jiangxi Guangchang Nanfeng tangerine cultivation system of lotus culture system, Shandong Zhangqiu, Henan Xin'an traditional onion cultivation system of Hunan Huayuan cherry cultivation system, sub La Gongmi integrated farming system.

\section{Problems in the protection of the cultural heritage of China's agricultural heritage}

From the macro perspective, with the acceleration of economic globalization and the rapid development of modernization, the social, economic and cultural aspects of our country is experiencing the transformation and development of complex and comprehensive, transformation and development, social contradiction and conflict in the traditional agricultural heritage is facing a serious threat of loss. With the rapid development of modern science and technology and the accelerating progress of agricultural science and technology, the traditional farming system and production mode are gradually replaced by modern farming technology and farming technology, and traditional feed has gradually changed to pesticides and chemical fertilizers.

Because of China's agricultural development has a long history, the differences of agricultural production conditions, in the form of many splendid Agricultural Cultural Heritage at the same time, also caused a number of agricultural heritage statistical uncertainty, effective excavation and protection of agricultural cultural heritage can not, and cannot further value evaluation and grade determination of agricultural heritage. From the microcosmic perspective, governments at all levels of awareness on the protection of agricultural heritage and pay enough attention to the one sidedness of the layer charge of the protection of cultural heritage, only pay attention to the cultural heritage declaration, the declaration did not carry out scientific protection and development of agricultural heritage, not from the importance of understanding the work related to the protection of human beings in the future the development of the. Only a single emphasis on the development of cultural heritage, its unique species resources, production technology, ecological environment and cultural benefits have not been developed accordingly. Although some heritage heritage and actively seek ways and means of agricultural heritage protection, but can effectively combine development and protection, the immediate and long-term, production function and ecological function, heritage of the interests of farmers and agricultural sustainable development problems, unified goal is difficult to achieve cultural heritage, ecological, social and economic benefits. Due to the development of urban-rural integration process, a large number of rural labor force of young migrant workers, leaving earth, abandoned farm, transfer to other industries in rural areas for labor weak elderly, women and children), from generation to generation skills facing the dilemma of leave no successor. China's agricultural cultural heritage protection consciousness needs to be improved. However, until now, the national government and the ordinary people have not yet formed a clearer understanding of the agricultural heritage.

\section{Suggestions}

The government should strengthen the degree of attention to the protection of agricultural heritage, in the world, continue to strengthen cooperation with FAO and other international organizations, research scholars and experts to send FAO, continuously consolidate and deepen our right to speak in the field of development; push related protection regulations, expand the international influence of China; a good grasp of the "The Belt and Road" international cooperation opportunities, exchanges with other countries and to explore the protection of agricultural heritage 
and development experience. Within the country, we should clarify the responsibilities of the relevant functional departments of the agricultural heritage, including making clear the formulation and implementation of the laws and regulations of the agricultural heritage, and their responsibilities. System and gradually improve the utilization of China's agricultural heritage protection and development, improve the agricultural heritage of relevant laws and regulations, such as "agricultural law" and other agricultural heritage related laws and regulations to enrich and increase agricultural cultural heritage protection and development and utilization etc..

Agricultural heritage protection should be without prejudice to the heritage location of residents and economic benefits, ecological benefits and social benefits, the heritage of residents on the dominant position, stimulate the enthusiasm of residents to participate in the heritage protection work, which added to the cultural heritage in agriculture. Therefore, it is especially important to build a multi - party social participation. To build a multi party participation mechanism, we can learn from the experience of the French government and give full play to the role of non-governmental organizations in the protection of cultural heritage. Adhere to the leading role of the government, encouraging care for agricultural heritage community play their enthusiasm, promote community members actively participate in heritage protection activities; in the strong support of science and technology, enterprises give capital, manpower, capital and other aspects of the fund, while the introduction of the whole tracking media publicity.

In terms of personnel development, learn from Japan and South Korea experience in professional training, the establishment of institutions of cultural heritage protection research in agricultural colleges, cultivation of cultural heritage protection personnel in many areas; hold regular exhibitions and lectures on the protection of agricultural heritage Agricultural Museum; at the same time between universities, research institutions, and local agricultural museum government departments should establish close contact and cooperation, jointly cultivate a group of agricultural heritage protection professionals. In addition, the government should give policy support and fund subsidy to the traditional agricultural technology inheritors, and encourage the cultivation of the successors of agricultural skills. We should enhance the publicity of agricultural cultural heritage protection by means of street media and public service advertisements, and constantly enhance public awareness of protection so as to create a good atmosphere for the protection, inheritance and development of Agricultural Cultural Heritage in China.

\section{Conclusions and Prospect}

The agricultural cultural heritage is part of our country's long and splendid culture. It is the responsibility and duty of every citizen to inherit and protect the agricultural cultural heritage. Although our country is difficult to determine the number, skills of leave no successor the protection of cultural heritage in agriculture, but as long as the government should pay more attention to improve, to build a multi participation mechanism, improve the public awareness of conservation, protection of Agricultural Heritage in China will get further development. With the development of the social economy and the improvement of the awareness of public protection, the protection of Agricultural Cultural Heritage in China will enter a new stage. The government and social organizations to protect the agricultural heritage, perfect the laws and regulations, strengthen enforcement, complete protection system, the establishment of long-term protection mechanism, carry out protection work before the project, the cultivation of professional talent, in the whole society to create a good atmosphere of the agricultural heritage protection wai. Thus, under the influence of a good social atmosphere, the public will also improve the awareness and attention of the agricultural cultural heritage.

\section{Acknowledgements}

Fund Project: Ministry of Education, China, Humanities and Social Science Fund Project (17YJA850009) 


\section{References}

[1] Zhou Y L, Shan-Shan L I. Current Situation and Development Strategies of Chinese Intangible Cultural Heritage Protection [J]. Journal of Xinzhou Teachers University, 2011.

[2] Zhang D Q. On Concept, Current Situation of Protection of Wuhan Intangible Cultural Heritage and Some Proposals [J]. Journal of Wuhan Institute of Technology, 2007.

[3] Yang B, Li H, He L, et al. Current Situation of China's Agricultural Cultural Heritage Protection [J]. Agricultural Outlook, 2017.

[4] Zhao D G. Present Situation of Sport Intangible Cultural Heritage Protection in Shaanxi Province and Countermeasures_-Red Fist: a Case Study[J]. Journal of Shaanxi University of Science \& Technology, 2012.

[5] Bao W. The General Situation of the Study of China's Intangible Cultural Heritage and Prospect: Based on CSSCI Journals in 2011-2016 Measurement and Visualization Analysis[J]. Pioneering with Science \& Technology Monthly, 2017.

[6] Zhu L P, Gao G H, Museum P. Current Situation and Protection of China's Cultural Heritage [J]. Value Engineering, 2013.

A brief introduction to the author: 1. Wang Benxue (1969), man, Enshi, Hubei, master and associate professor, the main research direction is regional economy. 2. Jing Kun (1979 ) woman, Benxi people of Liaoning, Ph. D., associate professor, main research direction: public policy and social governance 